\title{
Connection between Radial and Ulnar Nerves at Humeral Level And Its Clinical Significance: A Cadaveric Case Report
}

\author{
Conexión entre los Nervios Radial y Ulnar a Nivel Humeral \\ y su Importancia Clínica: Reporte de Caso en un Cadaver
}

Mohammad Mehdi Hassanzadeh Taheri* \& Mohammad Afshar**

TAHERI, M. M. H. \& AFSHAR, M. Connection between radial and ulnar nerves at humeral level and its clinical significance: A cadaveric case report. Int. J. Morphol., 33(4):1559-1562, 2015.

SUMMARY: Variations of the terminal branches of the brachial plexus in the upper limb are abundant and frequently have been reported. But connection between its radial and ulnar nerves at humeral level is very rare. During routine dissection of the right arm of a 75-year-old male cadaver in the Department of Anatomy of Birjand University of Medical Sciences (BUMS), in Iran, we observed a connection between radial and ulnar nerves, and from the literature reviewed, we found only two cases that had been reported previously, one of them was unilateral and the other bilateral. Awareness of such variations are very important for surgeons and diminish the possible complication of regional anesthesia and surgical procedures, hence, we decided to report it.

KEY WORDS: Radial nerve; Brachial plexus; Ulnar nerve; Anatomical variation; Connection.

\section{INTRODUCTION}

The brachial plexus is formed from joining of the lower four cervical ventral rami (C5-C8) with the major part of the first thoracic ventral ramus (T1). This plexus is located in the posterior triangle of the neck and also in the axillary fossa (Williams et al. 2005; Kocabiyik et al., 2007). The five roots combine to each other to form the upper, middle and lower trunks at the lateral border of anterior scalene muscle, then; each of the trunks bifurcates into anterior and posterior divisions in the floor of the posterior triangle of the neck. Thereafter, near the upper border of the first rib these divisions join each other to form lateral, medial and posterior cords. Finally, close to lower border of the pectoralis minor muscle, these cords form their terminal branches, including the musculocutaneous, axillary, median, ulna and radial nerves (Williams et al.; Kocabiyik et al.).

Brachial plexus lesions, or injuries, can occur as a result of shoulder tumors, trauma or inflammations and brachial plexus blockade carrying out in some surgical procedure on the upper limb like bone fractures, in patients with respiratory diseases such as: emphysema, bronchitis and etc. For this purpose, a precise understanding of the anatomy of the plexus is necessary as well as recognition of anatomic variations that may occur (Orebaugh \& Williams 2009; Ozguner et al., 2010; Snell, 2005).

The variation in the course, distribution and formation of the brachial plexus branches are common and usually have been reported by many authors (Aktan et al., 2001; Pandey \& Shukla, 2007). Variation in nerves with abnormal origin, distribution and course are usually more susceptible to entrapment neuropathies and iatrogenic injuries (Roberts, 1992).

Connection between some terminal branches of brachial plexus are numerous and frequently have been reported by some authors, but from the literature reviewed, we found only two cases of connection between radial and ulnar nerves in the arm that had been reported, one of them was unilateral and the other bilateral (Ozguner $e t$ al.; Ajayi et al., 2012).

\footnotetext{
* Ph.D, Associated Professor of Anatomical Sciences, Department of Anatomy, Faculty of Medicine, Birjand University of Medical Sciences, Birjand, Iran. ** Ph.D, Professor of Anatomical Sciences, Member of Medical Toxicology Research Center, Department of Anatomy, Faculty of Medicine, Birjand University of Medical Sciences, Birjand, Iran.
} 


\section{CASE REPORT}

During routine dissection of the right arm of a cadaver about 75-year-old male, in the Department of Anatomy in Birjand University of Medical Sciences (BUMS) as part of instruction of medical students, we observed a connection between radial and ulnar nerves on the anterior aspect of the middle two- fourth at humeral level. After precise and carefully dissection of the region and freeing the neighboring anatomic structures, the variant nervous connection measured precisely by an electronic digital caliper (TCM, made in German). Finally, the variant nerve with the other neighboring anatomic features such as; radial, ulnar and median nerves, ulnar collateral branch of radial nerve and brachial vessels stained and photos were taken (Figs. 1 and

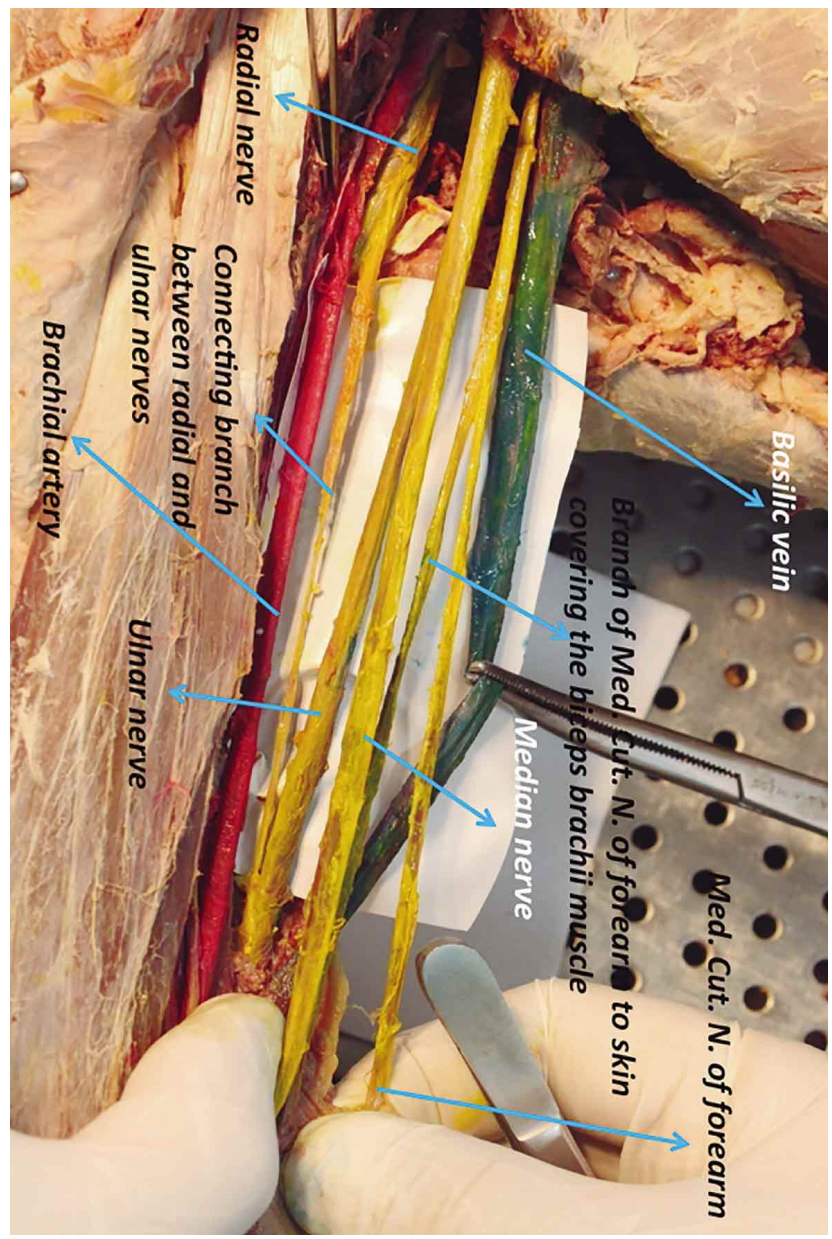

Fig. 1. A photograph of a dissected right side of the arm showing: Three branches of medial cord (median, ulnar and med. cut. n. of forearm nerves) and a branch of posterior cord (radial n.) of brachial plexus in the medial side of the right arm. Radial nerve connects to the ulnar nerve by a connecting branch with about $13 \mathrm{Cm}$ length and $1.5 \mathrm{~mm}$ diameter. Basilic vein (in the medial side) and Brachial artery (in the lateral side) also are observed in this picture.
2). The length of connecting branch between radial and ulnar nerves was about $13 \mathrm{~cm}$ and its diameter was about $1.5 \mathrm{~mm}$. This connecting branch originated from the radial nerve, in anterior aspect of the arm and descended in the medial side of the brachial artery and joined the ulnar artery in distal humeral level (Figs. 1 and 2). A nervous thin filament of the radial nerve named the ulnar collateral branch and terminates to medial head of triceps muscle, lied in the lateral side of the brachial artery. The reported variation was unilateral (right arm) and no connection observed in the left arm of the case.

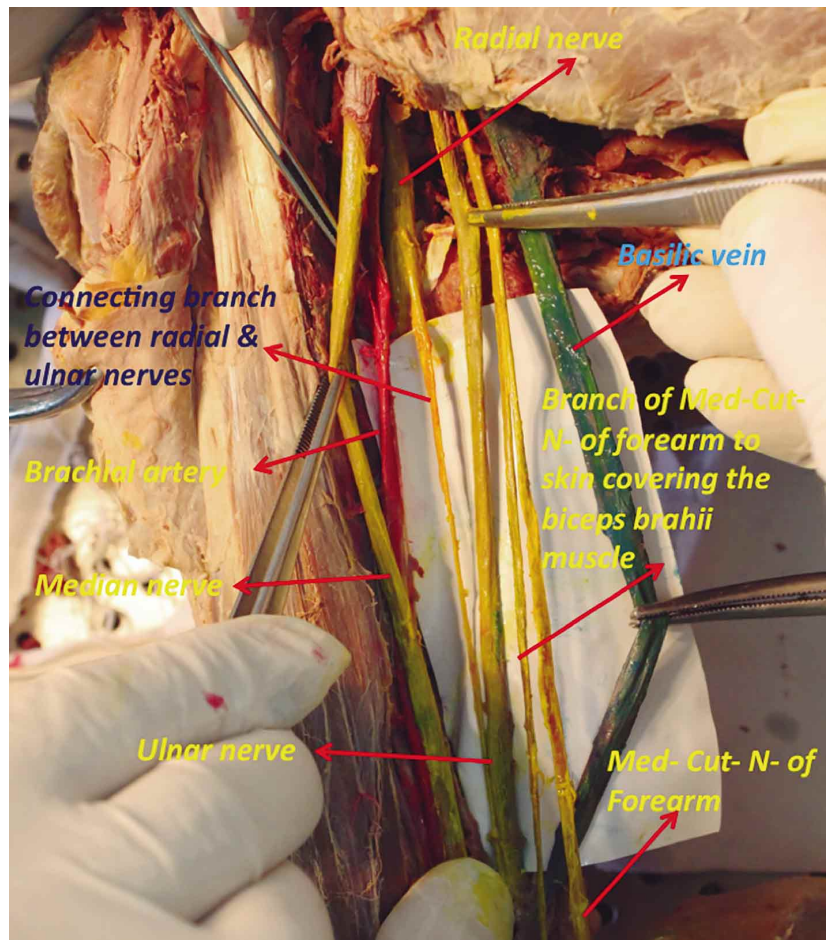

Fig. 2. A photograph of a dissected right side of the arm showing: Anterior view of brachial region at the right arm of cadaver. A connection nerve is observed clearly in this picture. It derives from radial nerve near the base of the axillary fossa and connects to the ulnar nerve at the middle two-fourth of arm.

\section{DISCUSSION}

Brachial plexus variations are numerous and some variations of its terminal branches in the arm and forearm frequently have been reported. Although, there are abundant reports of communications between radial and ulnar nerves on the dorsal surface of the hand, and different types of these connections have been reported (Loukas et al., 2008), but 
connection between radial and ulnar nerves at humeral level, has not been reported greatly. In Uysal et al. (2003) investigation that dissected 200 brachial plexus in human fetuses, 93 cases $(46.5 \%)$ had no variations, while, variations in $53.5 \%$ of them were observed. Variations in terminal branches of the plexus are also abundant and have also been reported, for example, variations of musculocutaneous nerve were classified by Guerri-Guttenberg \& Ingolotti (2009). Pattern of motor branching of this nerve in human fetuses were also studied by Kervancioglu et al. (2011). Communication between musculocutaneous and median nerves in arm has been observed in $46.4 \%$ studied cases by Choi et al. (2002). Frequency of this anomaly has been reported $63 \%$ by Loukas \& Aqueelah (2005). In Venieratos \& Anagnostopoulou investigation (1998), communication between median and ulnar nerves has been observed in $20 \%$ of studied cases. In another research this type of variation has been observed in 10 forearms of 163 studied cadavers (Kazakos et al., 2005). In oppose the stated variations, connection between radial and ulnar nerves in the arm or forearm are very rare and in literature reviewed, we found only two cases, which one of them was unilateral (Ozguner et al.) and the other bilateral (Ajayi et al.). Ozguner et al. reported a case of unilateral connection between radial and ulnar nerves at high humeral level on the left arm of a 75year-old male cadaver. The length and wide of this connecting branch were $6 \mathrm{~cm}$ and $3 \mathrm{~mm}$ respectively, while these measurements in our reported case were $13 \mathrm{Cm}$ long and $1.5 \mathrm{~mm}$ wide which its length was two times longer, while, its diameter was half, of their reported case (Ozguner et $a l$.). In another reported case a bilateral connection between radial and ulnar nerves has been reported by Ajayi et al. In their reported case on the right side, the radial and ulnar nerves had a single communicating branch whereas on the left side, there were multiple communication twigs between the two nerves at the mid humeral level (Ajayi et $a l$.). The authors not measured the connecting branches between radial and ulnar nerves.

The knowledge of variations in terminal branches of brachial plexus, such as their abnormal connections is invaluable in clinical practice especially in radiological diagnoses and surgical procedures and failure to recognize these variations can confuse the assessment of the severity of nerve injury as well as recovery (Leis \& Wells, 2008). These communications may create inappropriate nerve blockade and /or blockade of unexpected regions during anesthesia. The understanding of possible variations will also help specialists to reach proper diagnosis of sensorimotor symptoms (Pontell et al., 2011). Therefore, awareness of such variations can be important for clinician in order to diagnostic procedures and surgical intervention on clinical practices, because unfamiliar with this anomaly may lead to iatrogenic injuries during surgical procedures on this region.

\section{ACKNOWLEDGMENTS}

Authors of the article thank Mr Eslami for taking photographs.

TAHERI, M. M. H. \& AFSHAR, M. Conexión entre los nervios radial y ulnar a nivel humeral y su importancia clinica: Reporte de caso en un cadaver. Int. J. Morphol., 33(4):1559-1562, 2015.

RESUMEN: Las variaciones de los ramos terminales del plexo braquial en el miembro superior son abundantes y reportadas con frecuencia. Sin embargo, la conexión entre los nervios radial y ulnar a nivel humeral es muy rara. Durante la disección rutinaria de un brazo derecho en un cadáver de sexo masculino de 75 años, en el Departamento de Anatomía de la Birjand University of Medical Sciences (BUMS) en Irán, se observó una relación entre los nervios radial y ulnar. En la literatura, encontramos sólo dos casos que habían sido reportados previamente, uno bilateral y otro unilateral. Conocer estas variaciones es de importancia para los cirujanos, así como para disminuir posibles complicaciones en la colocación de anestesia regional y procedimientos quirúrgicos.

PALABRAS CLAVE: Nervio radial; Plexo braquial; Nervio ulnar; Variación anatómica; Conexión.

\section{REFERENCES}

Ajayi, N. O.; Lazarus, L. \& Satyapal, K. S. Multiple variations of the branches of the brachial plexus with bilateral connections between ulnar and radial nerves. Int. J. Morphol., 30(2):65660, 2012.

Aktan, Z. A.; Öztürk, L.; Bilge, O.; Özer, M. A. \& Pinar, Y. A. A cadaveric study of the anatomic variations of the brachial plexus nerves in the axillary region and arm. Turk. J. Med. Sci., 31:147-50, 2001.

Choi, D.; Rodríguez-Niedenführ, M.; Vázquez, T.; Parkin, I. \& Sañudo, J. R. Patterns of connections between the musculocutaneous and median nerves in the axilla and arm. Clin. Anat., 15(1):11-7, 2002. 
Guerri-Guttenberg, R. A. \& Ingolotti, M. Classifying musculocutaneous nerve variations. Clin. Anat., 22(6):671-83, 2009.

Kazakos, K. J.; Smyrnis, A.; Xarchas, K. C.; Dimitrakopoulou, A. \& Verettas, D. A. Anastomosis between the median and ulnar nerve in the forearm. An anatomic study and literature review. Acta Orthop. Belg., 71(1):29-35, 2005.

Kervancioglu, P.; Orhan, M. \& Kilinc, N. Patterns of motor branching of the musculocutaneous nerve in human fetuses and clinical significance. Clin. Anat., 24(2):168-78, 2011.

Kocabiyik, N.; Yalcin, B.; Kilic, C. \& Ozan, H. Multiple anomalies of the brachial plexus: A case report. Neuroanat., 6:21-3, 2007.

Leis, A. A. \& Wells, K. J. Radial nerve cutaneous innervation to the ulnar dorsum of the hand. Clin. Neurophysiol., 119(3):6626, 2008.

Loukas, M. \& Aqueelah, H. Musculocutaneous and median nerve connections within, proximal and distal to the coracobrachialis muscle. Folia Morphol. (Warsz), 64(2):101-8, 2005.

Loukas, M.; Louis, R. G. Jr.; Wartmann, C. T.; Tubbs, R. S.; TuranOzdemir, S. \& Kramer, J. The clinical anatomy of the communications between the radial and ulnar nerves on the dorsal surface of the hand. Surg. Radiol. Anat., 30(2):85-90, 2008.

Orebaugh, S. L. \& Williams, B. A. Brachial plexus anatomy: normal and variant. ScientificWorldJournal, 9:300-12, 2009.

Ozguner, G.; Desdicioglu, K. \& Albay, S. Connection between radial and ulnar nerves at high humeral level. Int. J. Anat. Var., 3:49-50, 2010.

Pandey, S. K. \& Shukla, V. K. Anatomical variations of the cords of brachial plexus and the median nerve. Clin. Anat., 20(2):1506, 2007.

Pontell, M.; Scali, F. \& Marshall, E. A unique variation in the course of the musculocutaneous nerve. Clin. Anat., 24(8):968-70, 2011.

Roberts, W. H. Anomalous course of the median nerve medial to the trochlea and anterior to the medial epicondyle of the humerus. Ann. Anat., 174(4):309-11, 1992.

Snell, R. S. Clinical Anatomy for Medical Students. $6^{\text {th }}$ ed. Boston, Little Brown \& Company, 2005. p.915.

Uysal, I. I.; Seker, M.; Karabulut, A. K.; Büyükmumcu, M. \& Ziylan, T. Brachial plexus variations in human fetuses. Neurosurgery, 53(3):676-84, 2003.

Venieratos, D. \& Anagnostopoulou, S. Classification of communications between the musculocutaneous and median nerves. Clin. Anat., 11(5):327-31, 1998.
Williams, P. L.; Bannister, L. H.; Berry, M. M.; Collins, P.; Dyson, M.; Dussek, J. E. \& Ferguson, M. W. J. Gray's Anatomy. $38^{\text {th }}$ ed. Edinburgh, Churchill Livingstone, 2005.

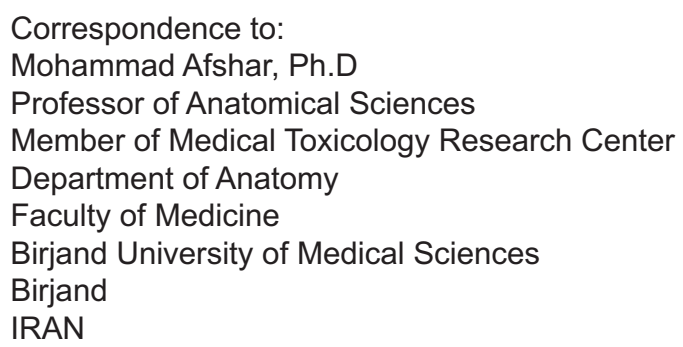

Tel: +985614433002

Fax: +985614433004

Email: afshr_md@yahoo.com

Received: 12-05-2015

Accepted: 22-09-2015 